\title{
Semicircular Canal Afferents Similarly Encode Active and Passive Head-On-Body Rotations: Implications for the Role of Vestibular Efference
}

\author{
Kathleen E. Cullen ${ }^{1}$ and Lloyd B. Minor ${ }^{2}$ \\ ${ }^{1}$ Aerospace Medical Research Unit, Department of Physiology, McGill University, Montreal, Quebec, Canada H3G 1 Y6, \\ and ${ }^{2}$ Department of Otolaryngology - Head and Neck Surgery, Department of Biomedical Engineering, and Department \\ of Neuroscience, The Johns Hopkins University, Baltimore, Maryland 21093
}

The vestibular receptors in the labyrinth receive innervation from centrifugally projecting efferent fibers. The influence of these efferents on information processing by vestibular afferents in primates has not been determined. One commonly held notion is that efferent activation during large-amplitude, active head movements would result in an increase in the resting discharge rate and in a reduction of the rotational sensitivity of afferents. Such an effect would increase the dynamic range of afferents involved in the encoding of head movements. To test this hypothesis, we recorded from afferents innervating the semicircular canals in alert macaques during passive head-onbody rotations and during active head movements that included gaze shifts and gaze pursuit. Extracellular, single-unit recordings were obtained from 24 afferent fibers innervating the horizontal, superior, and posterior canals. Based on the nor- malized coefficient of variation of the interspike interval for these units, our sample contained six regularly discharging, six intermediate, and 12 irregularly discharging afferents. Responses were analyzed using a least squares regression to determine the bias discharge rate of each unit and sensitivity to head velocity and acceleration. We found no difference in bias discharge rate or rotational sensitivity of the afferent responses for the different stimulus conditions tested. Our results indicate that semicircular canal afferents encode information about head rotation similarly for self generated and passively applied headon-body movements.

Key words: vestibular; labyrinth; semicircular canals; vestibular afferents; vestibular efferents; active head movement; gaze shifts; pursuit
The role of the vestibular efferents in the processing of information about head motion in primates has been a mystery. The vestibular receptors receive innervation from centrifugally projecting efferent fibers (Rasmussen and Gacek 1958; Gacek and Lyon, 1974). The efferent cell group in primates is made up of $\sim 400$ neurons that are located in the brainstem immediately lateral to the abducens nucleus (Goldberg and Fernández, 1980). Efferent axons project bilaterally to each labyrinth and make contacts presynaptically onto type II hair cells and postsynaptically onto the axons of vestibular afferents (Lindeman, 1969; Klinke and Galley, 1974; Sans and Highstein, 1984). In frogs (Valli et al., 1986) and presumably in mammals (Purcell, 1997), the efferent innervation pattern is diffuse with individual fibers terminating onto multiple hair cells and onto afferents that arise from different vestibular endorgans.

Efferent control of vestibular end organs has been studied in a number of species including frogs, fish, turtles, birds, chinchillas, and monkeys (Goldberg et al., 2000). In toadfish and in barbiturate-anesthetized squirrel monkeys, electrical activation of the vestibular efferents results in an increase in the resting discharge rate of vestibular nerve afferents (Goldberg and Fer-

Received Jan. 25, 2002; revised Feb. 27, 2002; accepted March 12, 2002.

This work was supported by the Canadian Institutes of Health Research and by National Institute of Health Grant R01 DC02390. We thank Jefferson Roy for assistance with the recording experiments. We also thank Jefferson Roy and PierreAlexandre Sylvestre for critically reading this manuscript.

Correspondence should be addressed to Dr. Kathleen E. Cullen, Aerospace Medical Research Unit, McGill University, 3655 Promenade Sir William Osler, Montreal, Quebec, Canada H3G 1Y6. E-mail: cullen@med.mcgill.ca.

Copyright (C) 2002 Society for Neuroscience $0270-6474 / 02 / 220001-07 \$ 15.00 / 0$ nández, 1980; Highstein and Baker, 1985). Further evidence of an excitatory action of efferents on afferent discharge rate is provided by studies in chinchilla (Plotnik et al., 2000). More heterogenous effects have been reported in frogs (Bernard et al., 1985; Rossi and Martini, 1991) and turtles (Brichta and Goldberg, 2000).

There are several lines of evidence that suggest that efferent innervation of the labyrinth might be used to change the background discharge rate and/or the sensitivity to motion of vestibular nerve afferents. First, experiments in alert toadfish have demonstrated that the modulation of semicircular canal afferents to passive head rotations decreases during electrical activation of efferent fibers. Second, toadfish efferent activation accompanies the responses leading up to an escape reaction (Highstein and Baker, 1985; Boyle and Highstein, 1990). Immediately before this reaction, efferents were found to generate a burst of activity. The behaviorally induced excitation of the efferents led to an increase

This article is published in The Journal of Neuroscience, Rapid Communications Section, which publishes brief, peerreviewed papers online, not in print. Rapid Communications are posted online approximately one month earlier than they would appear if printed. They are listed in the Table of Contents of the next open issue of JNeurosci. Cite this article as: JNeurosci, 2002, 22:RC226 (1-7). The publication date is the date of posting online at www.jneurosci.org.

http://www.jneurosci.org/cgi/content/full/6418 
in the discharge rate and a decrease in the rotational sensitivity of afferents when assessed by passive head rotation. Third, in primates, the vestibular sensitivity of non-eye movement-related second-order vestibular nuclei neurons, which are thought to mediate the vestibulocollic reflex, is selectively attenuated for self-generated head-on-body rotations (Gdowski and McCrea, 1999; Roy and Cullen, 2001). The site of the behaviorally dependent modulation of vestibular processing is unknown. A direct, efferent-mediated reduction of the head velocity signal that these neurons receive from vestibular nerve afferents would be one mechanism that could produce these behaviorally contingent changes in the encoding of head movements. Taken together, these findings are consistent with the hypothesis that the role of the efferent vestibular system is to increase the linear range of afferent responses during active head movements by increasing their background discharge and decreasing their rotational sensitivities (for review, see Goldberg et al., 2000; Purcell and Perachio, 2001). Accordingly, we sought to test whether vestibular efferents change the discharge rate and rotational sensitivity of semicircular canal afferents during different conditions of head and eye movement.

\section{MATERIALS AND METHODS}

Two monkeys (a Macaca mulatta and a Macaca fasicularis) were prepared for chronic extracellular recording. The procedures recently described (Sylvestre and Cullen, 1999) were used for the surgical preparation of monkeys. A stainless steel recording chamber was positioned stereotaxically on the skull to record from the vestibular nerve at the point at which it emerged from the internal auditory meatus. We approached the vestibular nerve through the floccular complex, which was identified by its eye movement-related activity (Lisberger and Pavelko, 1986). Entry to the nerve was preceded by a silence, indicating that the electrode had left the cerebellum, and after exiting the nerve we were able to determine (as infrequently as possible) the location of the base of the skull by the abrupt appearance of $60 \mathrm{~Hz}$ noise. Before the recording experiments, the location of the nerve was confirmed in both monkeys as follows: first, a guide tube was advanced through an $X-Y$ stage (Narishige, Tokyo, Japan), which was attached to the monkey's recording chamber, to a depth estimated to be $1.5 \mathrm{~mm}$ above the nerve. Second, the proximity of the guide tube to the internal auditory meatus was then verified by anesthetizing the monkeys and making x-ray images of their heads in the horizontal, sagittal, and frontal planes. In one animal, the location of the microelectrode within the vestibular nerve was later histologically confirmed. All experimental protocols complied with the guidelines of the Canadian Council on Animal Care and National Institutes of Health and were approved by the Animal Care Committee of McGill University and by the Animal Care and Use Committee of the Johns Hopkins University School of Medicine.

During the experiments, the monkey was seated in a primate chair. For six afferents, horizontal and vertical gaze and head movements were recorded using the magnetic search coil technique (Fuchs and Robinson, 1966). For the remaining afferents, horizontal, vertical, and torsional head movements were measured using two orthogonally placed coils that were secured to the animal's head implant. For vertical and horizontal canal units, we analyzed only those head movements for which the amplitude of the torsional component was $<15 \%$ of the vertical or horizontal component, respectively. The extracellular recording techniques that were used have been recently described (Hullar and Minor, 1999; Sylvestre and Cullen, 1999). Monkeys generated voluntary eyehead movements to track a food target, which was alternatively presented on either side of an opaque screen facing the monkey (gaze shifts; Guitton et al., 1984), or which was slowly moved in front of the monkey to elicit eye-head pursuit. To investigate each the response of each afferent during passive head rotations, the experimenter manually rotated the animal's head on its neck to induce head-on-body movements with trajectories comparable to those generated during voluntary gaze shifts and pursuit (peak head velocity $= \pm 100-400 \% \mathrm{sec}$ and predominate frequency $0.5-1.5 \mathrm{~Hz}$ ). Behavioral paradigms, target, head motion, and the storage of data were controlled by a UNIX-based real-time data acquisition program, and all data were recorded on a DAT tape for later playback and analysis. Off-line, gaze, and head position signals were low-pass filtered at $250 \mathrm{~Hz}$ (8 pole Bessel filter) and sampled at $1000 \mathrm{~Hz}$. These signals were digitally filtered at $125 \mathrm{~Hz}$ and differentiated to produce velocity signals.

The spike train of each vestibular afferent was analyzed off-line. A windowing circuit (BAK Electronics Inc., Germantown, MD) was set manually to generate a pulse coincident with the rising phase of each action potential. The neural discharge was represented using a spike density function in which a Gaussian was convolved with the spike train (Cullen et al., 1996). The resting discharge of each unit and coefficient of variation of the interspike interval $(\mathrm{CV})$ were determined. A normalized coefficient of variation $\left(\mathrm{CV}^{*}\right)$ was calculated using the method described by Goldberg et al. (1984). A least-squared regression analysis was then used to determine the modulation bias of each unit (bias = spikes per second), head velocity sensitivity $\left(g_{\mathrm{v}}=\right.$ spikes per second/degrees per second $)$, and head acceleration sensitivity $\left(g_{\mathrm{a}}=\right.$ spikes per second $/$ degrees per second) during passive and self-generated head motion. Afferents were typically driven into the nonlinear range (inhibitory cutoff) for large-velocity head movements in their off direction. Accordingly, fits to the passive and active rotations were made based on responses that were $>10$ spikes/sec. During on-direction rotations, afferents were rarely driven into saturation. Nevertheless, because afferent neurons typically discharge at rates less than $\sim 300$ spikes/sec, data for which the firing rate was greater than this value were not included in the optimization. Because the firing rate bias of each afferent was estimated during passive and active head motion, rather than constraining it to the value of its resting discharge, the influence of the type of distortion that has been reported by Fernández and Goldberg (1971) would have been minimal.

The semicircular canal innervated by each afferent was determined based on the responses of the afferent to manually delivered rotations. Horizontal canal afferents were excited by rotations toward the side of the recording, anterior canal afferents by downward rotations, and posterior canal afferents by upward rotations. The active and passive rotational sensitivities of horizontal and vertical canal units were quantitatively characterized during horizontal and vertical head rotations, respectively. We restricted our analysis to those movements for which the amplitude of head motion was at least $95 \%$ in the horizontal plane for horizontal canal units and at least $95 \%$ in the vertical plane for vertical canal units. Because the head rotations for vertical canal units were not in the plane of the canal, trigonometric corrections were made for the sensitivities of these units from the pitch and roll components of the head rotations as we have described (Hullar and Minor, 1999).

\section{RESULTS}

\section{Afferent responses during passive head movements}

The responses of 24 vestibular nerve afferents that were sensitive to rotational head movements, but not to static tilts, were recorded in two monkeys. When classified based on the plane and direction of rotation that led to maximum activation during passive head-on-body rotation, there were 8 horizontal canal, 11 superior canal, and 5 posterior canal afferents. When classified based on regularity of discharge, there were 6 regularly discharging $\left(\mathrm{CV}^{*}<0.1\right), 6$ intermediate $\left(\mathrm{CV}^{*}=0.1-0.2\right)$, and 12 irregularly discharging $\left(\mathrm{CV}^{*}>0.2\right)$ afferents. There were two irregularly discharging afferents with rotational sensitivity $<0.5$ spikes/sec per \%sec. Based on the relationship between $\mathrm{CV}^{*}$ and rotational sensitivity for dimorphic and calyx-only units described by Lysakowski et al. (1995), these two irregularly discharging afferents were likely to be calyx-only units, and the other 10 irregular afferents were likely to be dimorphic. The mean resting discharge rates were $99 \pm 26$ spikes/sec (mean $\pm \mathrm{SD}$ ) for regular afferents, $113 \pm$ 36 spikes/sec for intermediate, and $87 \pm 48 \mathrm{spikes} / \mathrm{sec}$ for irregular units. The rotational sensitivity of each neuron was calculated by estimating the coefficients for the following model:

$$
F R(t)=\text { bias }+g_{\mathrm{v}} \dot{H}(t)+g_{\mathrm{a}} \ddot{H}(t),
$$

where $F R$ is firing rate, $\dot{H}$ is head velocity, $g_{\mathrm{v}}$ is the sensitivity to head velocity, $\ddot{H}$ is head acceleration, and $g_{\text {a }}$ is the sensitivity to head acceleration. The velocity sensitivity calculated from passive 
head rotations was as follows: $0.47 \pm 0.26$ spikes/sec per $\% / \mathrm{sec}$ for regular afferents, $1.26 \pm 0.81$ spikes/sec per $\%$ sec for intermediate afferents, $1.13 \pm 0.55$ spikes $/ \mathrm{sec}$ per $\% \mathrm{sec}$ for dimorphic irregular units, and $0.36 \pm 0.10 \mathrm{spikes} / \mathrm{sec}^{\mathrm{per}} \% \mathrm{sec}$ for calyx irregular units. These values are similar to those reported in previous studies of semicircular canal afferents in alert macaques (Keller, 1976; Lisberger and Pavelko, 1986). The mean acceleration sensitivity was $0.002 \pm 0.001 \mathrm{spikes} / \mathrm{sec}$ per $\% \mathrm{sec}^{2}$ and did not differ between the various classes of neurons in this study.

\section{Afferent responses during active head movements}

The responses of a posterior canal afferent with intermediate discharge regularity $\left(\mathrm{CV}^{*}=0.10\right)$ to passive and active head rotations are shown in Figure 1. The fit of Equation 1 to the passive head rotation is shown in Figure $1 A$. To determine if there were any changes in the afferent responses to active in comparison to passive head movements, we used the model based on passive head rotations to predict the responses under the active head movement conditions (Fig. 1B,C, heavy traces). The voluntary, active head movements were generated during (1) combined eye-head tracking (gaze pursuit, Fig. 1B) and (2) eye-head gaze shifts (Fig. $1 C$ ). This afferent was typical of all units in our sample in that its modulation was similar during passive and active head-on-body rotations. Furthermore, note that in the interval immediately after gaze shift, denoted by the vertical arrows in Figure $1 C$, gaze is held fixed in space while the head is still moving. The discharge of the neuron continued to modulate in relationship to head velocity, as predicted by the responses during passive head rotation during all portions of this record.

To further investigate any changes in afferent responses between passive and active head movement, we selected intervals of head rotation that were of comparable frequency and velocity in the two conditions. Figure 2 shows a horizontal canal regularly discharging afferent $\left(\mathrm{CV}^{*}=0.06\right)$ during similar passive and active head rotations. The head was moving left and right at a frequency of $\sim 1 \mathrm{~Hz}$ and at a peak velocity ranging from 70 to 200 $\%$ sec. The fit of Equation 1 to the data from passive rotation is shown in Figure $2 A$. The bias discharge rate, velocity sensitivity, and acceleration sensitivity of the afferent measured 70 spikes/ sec, 0.36 spikes/sec per $\% / \mathrm{sec}^{2}$, and 0.0002 spikes/sec per $\% / \mathrm{sec}^{2}$, respectively during this stimulus condition. The fit of Equation 1 to the data from active rotation is shown in Figure $2 B$. The bias rate, velocity sensitivity, and acceleration sensitivity of the afferent were 71 spikes/sec, 0.32 spikes/sec per $\%$ sec, and 0.0002 spikes/ sec per $\%$ sec, respectively, during this stimulus condition. We also used the coefficients of the fit to the passive rotation data to predict the response to the active rotation. The goodness of fit in each stimulus condition was evaluated with a measure of variance-accounted-for (VAF). The VAF for the prediction using the passive model to fit the data from active rotation was 0.93 , which was comparable to VAF of the passive (0.97) and active (0.95) fit estimates.

\section{Responses during passive and active head movements were comparable}

Figure 3, $A$ and $B$, presents a comparison of the bias discharge rate and rotational sensitivity, respectively, for the fits to the data from the active and passive rotations. The regression equations relating these data were:

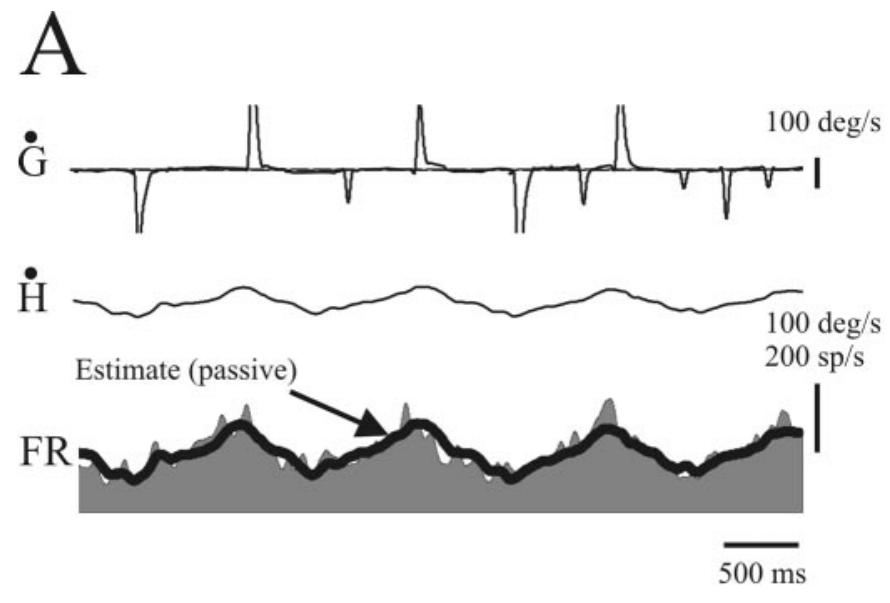

$\mathrm{B}$
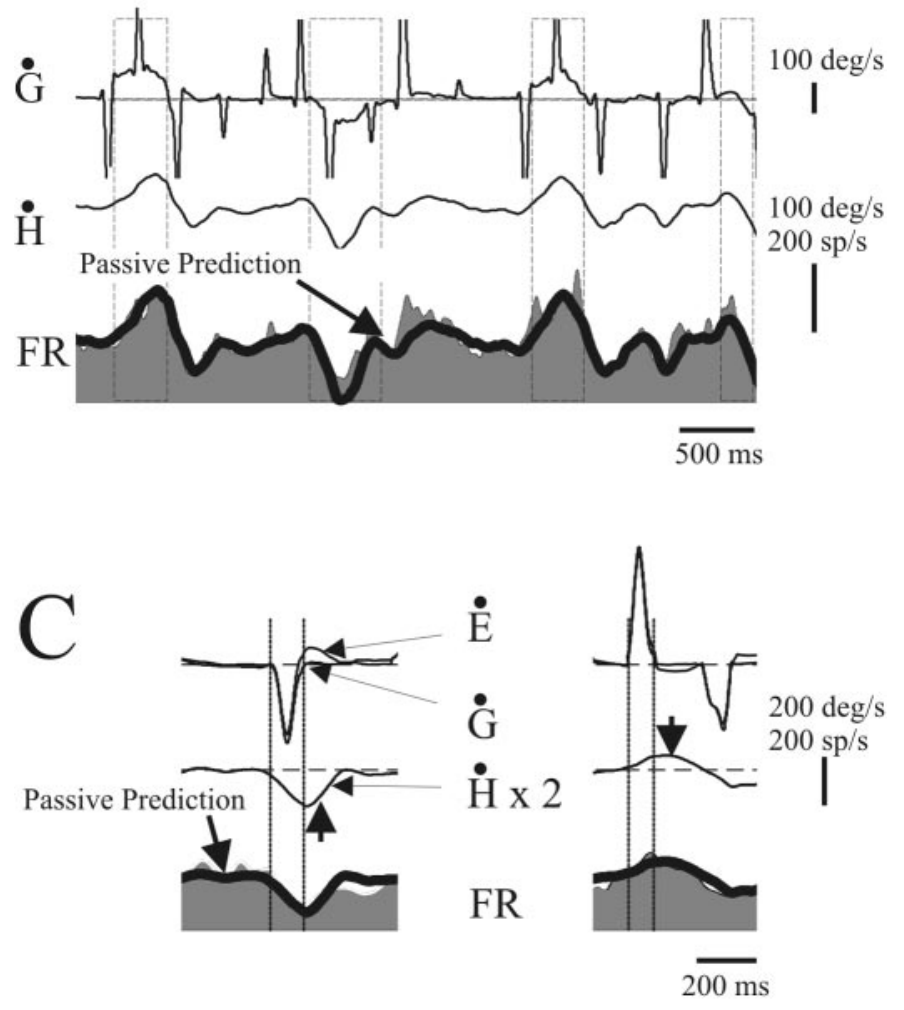

Figure 1. Activity of an afferent innervating the posterior canal during passive head rotations $(A)$, combined eye-head pursuit $(B)$, and combined eye-head gaze shifts $(C)$. A model based on passive head movement sensitivities (dark traces) is superimposed on the firing rate profiles (shaded traces). This model provided an accurate prediction of the afferent firing rate in all conditions. Upward directed traces denote upward moving eye, head, and gaze velocities. Horizontal lines indicate velocities of $0 \%$ sec. The rectangles in $B$ indicate intervals of gaze pursuit during which head movements were generated. The vertical arrows in $C$ indicate the interval immediately after the gaze shift where gaze is stable but the head continues to move. Vertical lines in $C$ indicate the onset and offset of gaze shifts using a $\pm 20 \%$ sec criterion. $F R$, Firing rate; $\dot{G}$, horizontal gaze velocity; $\dot{E}$, horizontal eye velocity; $\dot{H}$, horizontal head velocity.

$$
\begin{gathered}
\operatorname{Bias}_{\text {active }}=17+0.85 \times \operatorname{Bias}_{\text {passive }}(r=0.90 ; p<0.0001) \\
g_{\text {v-active }}=0+0.87 \times g_{\mathrm{v} \text {-passive }}(r=0.90 ; p<0.0001) .
\end{gathered}
$$



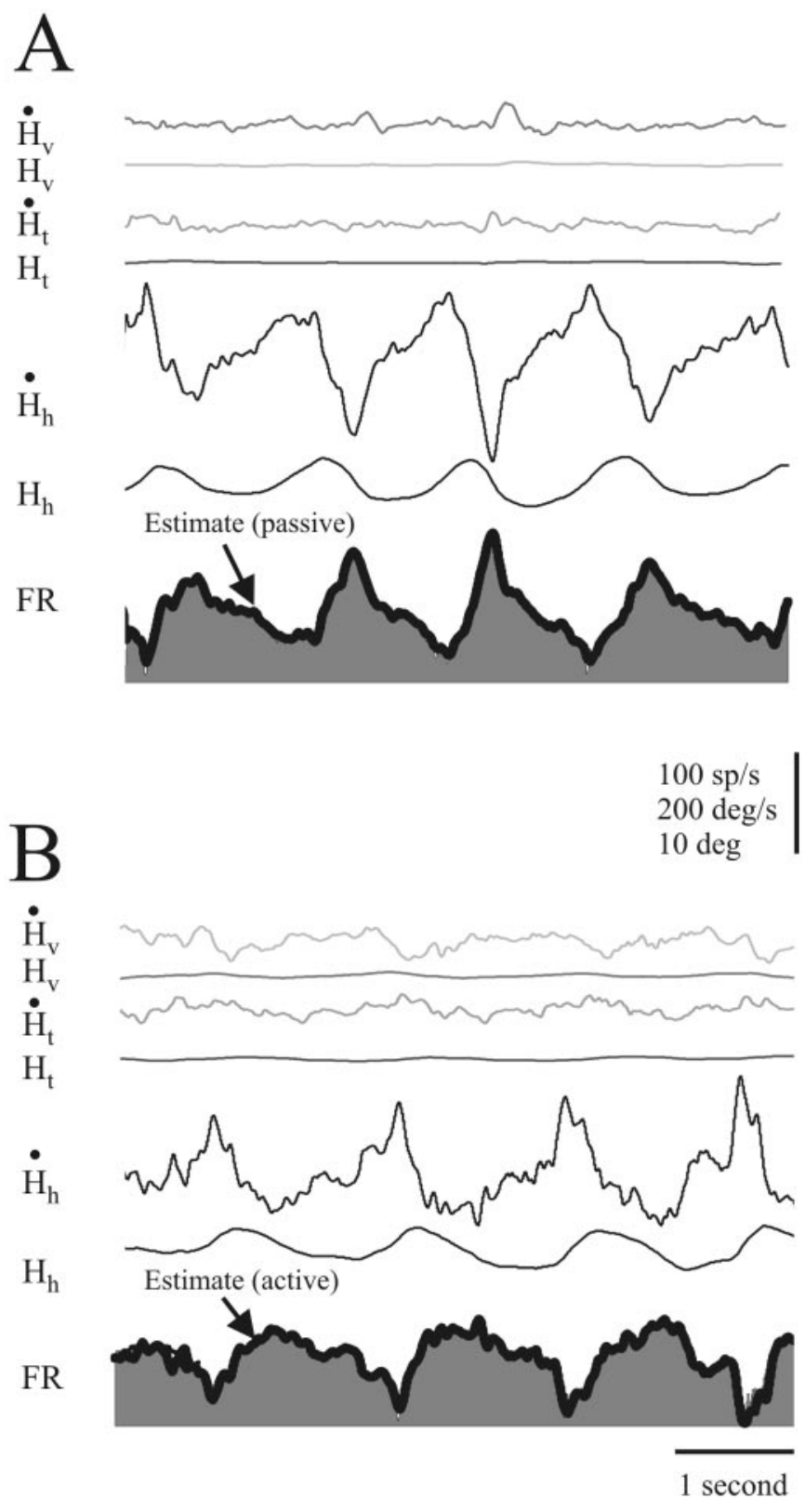

Figure 2. Activity of an example horizontal canal afferent during passive head-on-body rotations $(A)$ and active head movements $(B)$. Models based on discharge bias, head velocity sensitivity, and head acceleration sensitivity (dark traces) were estimated separately to describe afferent response during passive and self-generated head-on-body rotations. Excellent fits were obtained in both conditions. $H_{\mathrm{h}}, H_{\mathrm{v}}$, and $H_{\mathrm{t}}$, Horizontal, vertical, and torsional head position; $\dot{H}_{\mathrm{h}}, \dot{H}_{\mathrm{v}}$, and $\dot{H}_{\mathrm{t}}$, horizontal, vertical, and torsional head velocity.

The mean bias discharge measured across afferents from the fits for the passive rotations was $112 \pm 47$ spikes/sec and was $112 \pm$ 45 spikes/sec for the active rotations (paired $t$ test; $p=1.0$ ). The mean velocity sensitivity of the afferents for passive rotations was $0.94 \pm 0.64 \mathrm{spikes} / \mathrm{sec}$ per $\% / \mathrm{sec}$, and the mean for active rotations was $0.91 \pm 0.61$ spikes $/$ sec per $\%$ sec (paired $t$ test; $p=0.7$ ). Moreover, the acceleration sensitivity of the 24 afferents was not different during active rotations $(0.002 \pm 0.002$ spikes $/$ sec per $\% \mathrm{sec}^{2}$ ) in comparison with the passive stimulus condition (paired $t$ test; $p=0.3$ ). Afferents were typically driven into inhibitory cutoff during portions of the stimulus record that were $>100 \% \mathrm{sec}$
A

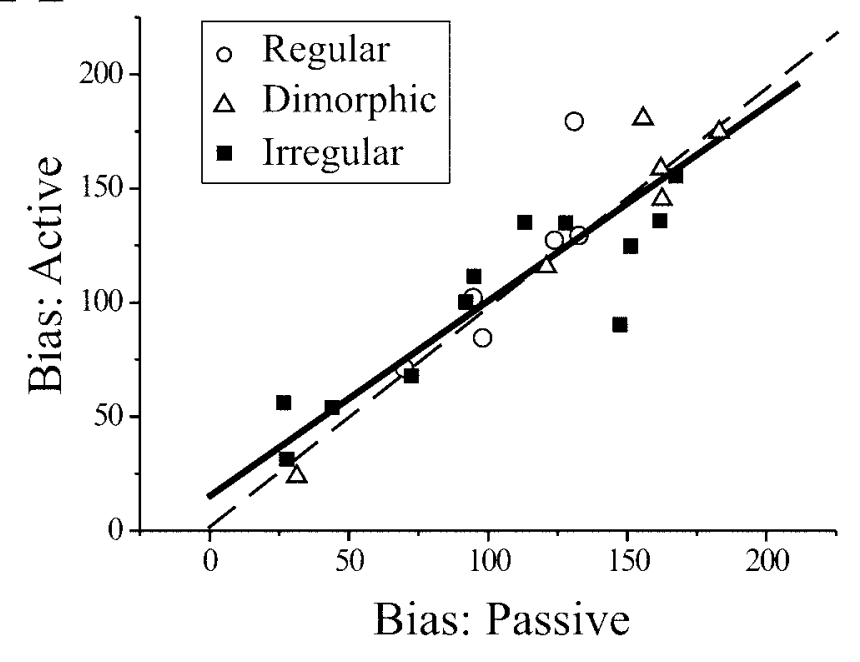

B

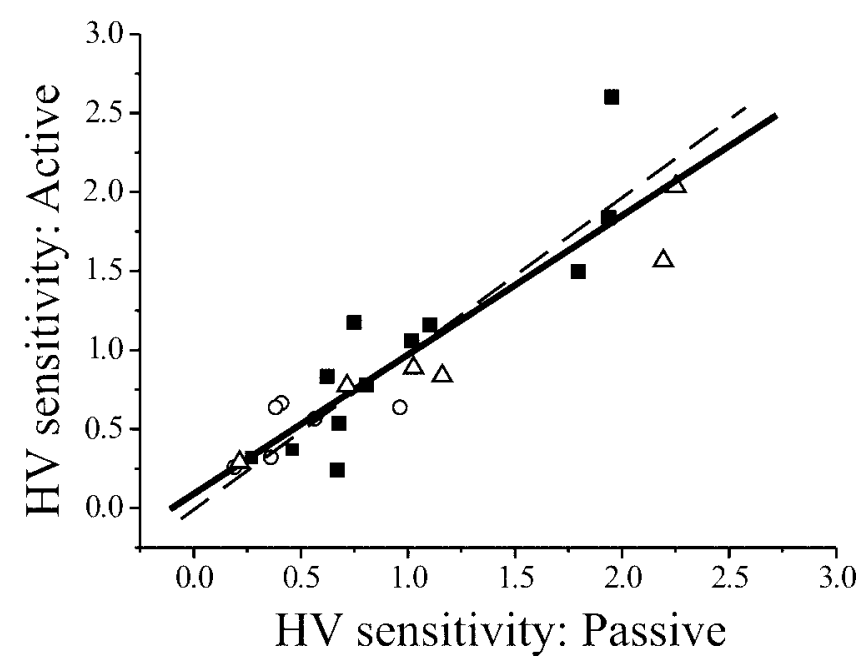

Figure 3. Comparison of model fits to the data from active and passive rotations for the 24 afferents in this study. Neither mean bias discharges $(A)$, head velocity sensitivities $(B)$, nor head acceleration sensitivities (data not shown) differed significantly across cells. To facilitate comparison, lines of unity slope for which the $y$-intercept $=0$ (dashed lines) are superimposed on each plot.

for high-gain irregular afferents and $>200 \%$ sec for regular and low-gain irregular afferents. Optimization for fits to the passive and active rotations were made based on responses that were not in inhibitory cutoff. The bias and sensitivity coefficients measured from these fits provided an accurate prediction of head velocity at which the afferent entered into and emerged from inhibitory cutoff for both the active and passive conditions. Thus, the afferent response dynamics did not differ for active and passive head movements.

This conclusion was further strengthened by the finding that the coefficients estimated in Equation 1 for the data from passive rotations provided an excellent predictive fit to the data from the active rotations. Indeed, the difference between the predicted VAF (coefficients from the fit to passive rotation data applied to active rotation condition) and the VAF calculated from the best 

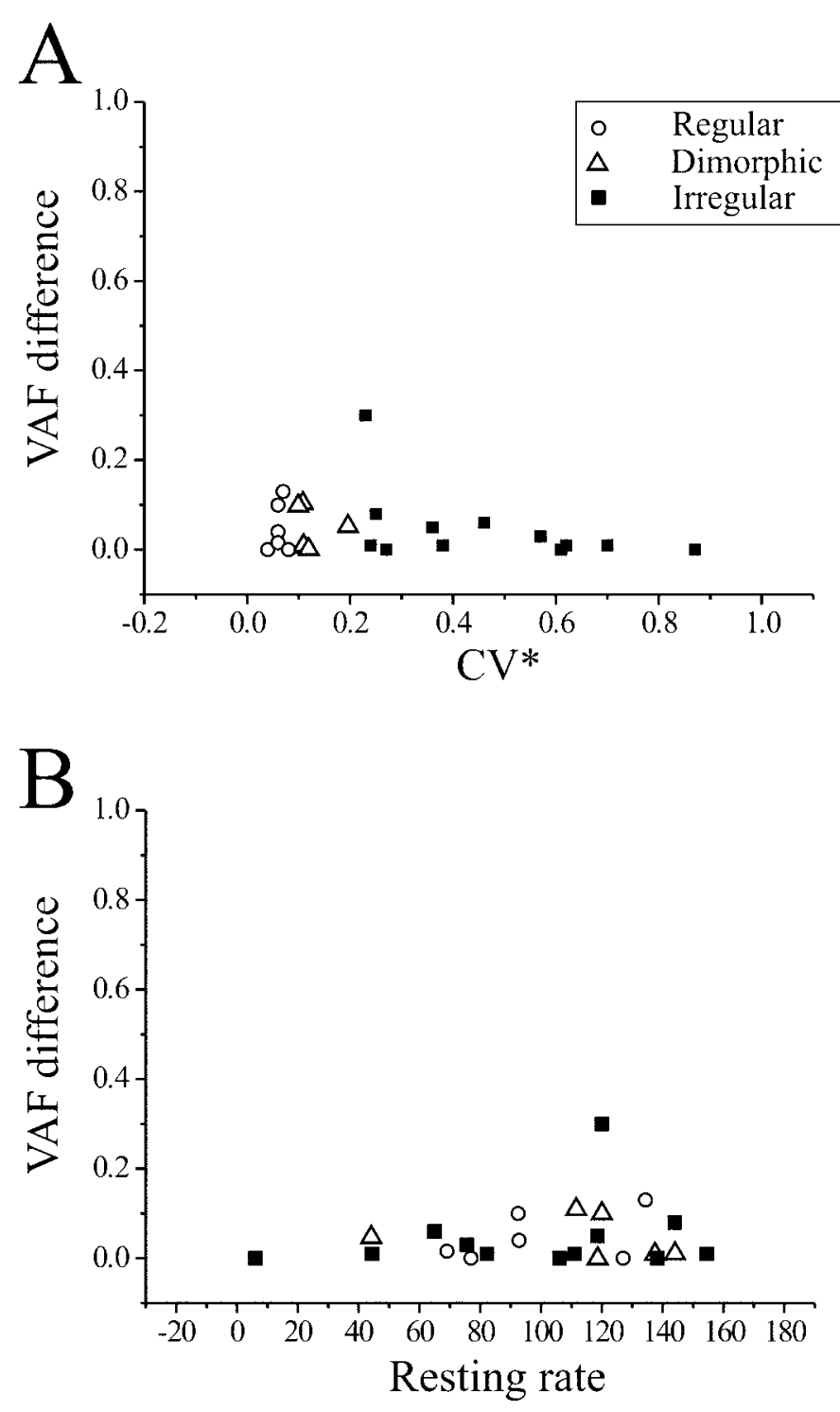

Figure 4. The VAF difference for each neuron was calculated by subtracting the predicted VAF (determined by applying model fits from passive rotation data to the active rotation condition) from the VAF calculated from the best model fit to the active-rotation data. The resultant difference in VAF was small, and was comparable across neurons regardless of $\mathrm{CV}^{*}(A)$ and resting discharge rate $(B)$.

fit to the active-rotation data was 0.04 (9\% of VAF for the optimal fit). Furthermore, this difference in VAF was comparable across neurons regardless of $\mathrm{CV}^{*}$ and resting discharge rate $\left(\mathrm{CV}^{*}\right.$ vs difference in VAF, $r^{2}=0.04, p=0.3$; resting discharge rate vs difference in VAF, $r^{2}=0.04, p=0.48$ ). These relationships are shown in Figure 4, $A$ and $B$, respectively.

\section{DISCUSSION}

The principal hypothesis investigated in this study was that vestibular efferents function to increase the background firing rate and decrease the rotational sensitivity of vestibular afferents during actively generated head movement, thereby decreasing the probability of inhibitory cutoff or excitatory saturation of these afferents. Our findings provide evidence that this hypothesis is incorrect for afferents innervating the semicircular canals in primates. These afferents were characterized during active rotations made during gaze shifts and gaze pursuit and during passively applied head-on-body movements with comparable trajectories. Afferents responded identically to actively and passively generated head-on-body rotations. Accordingly, we conclude that the vestibular efferent system does not differentially modulate afferent responses during self-generated versus passive head rotations.

\section{Implications for the central processing of vestibular information}

Recent studies have shown that the vestibular neurons, which receive direct inputs from vestibular afferents, do not reliably encode head-in-space velocity during the active head movements made during gaze shifts and gaze pursuit. The vestibular sensitivity of non-eye-movement-related second order vestibular nuclei neurons, which are thought to mediate the vestibulocollic reflex, is selectively attenuated for self-generated, head-on-body rotations (Roy and Cullen, 2001). In addition, the vestibular signals carried by interneurons involved in control of the vestibuloocular reflex (VOR) are reduced during these combined eyehead movements (McCrea et al., 1996; Roy and Cullen, 1998; Cullen et al., 2001). At first glance, it would seem that a likely explanation for these results could be that the vestibular afferent input to these neurons is selectively suppressed during selfgenerated head rotations. However, there are two points to consider: first, the head velocity signals carried by VOR interneurons are suppressed whenever the visual axis of gaze is redirected, regardless of whether head rotations are self-generated or externally applied (Cullen et al., 2001). Second, responses are only attenuated when the behavioral goal is to redirect gaze and are unchanged during self-generated head movements when gaze is stable. Thus, these results suggest that the vestibular afferent input to the vestibular nuclei neurons is not selectively suppressed during self-generated head motion. The findings of our present study confirm and complement these previous results and show that semicircular canal afferents encode rotation velocity identically for active and passive head rotations.

\section{Comparison with previous studies of vestibular efferents}

In a previous series of investigations of the effects of efferent activation on the responses of vestibular afferents in the toadfish, Highstein and Baker (1985), Boyle and Highstein (1990), and Highstein $(1991,1992)$ showed that preceding an escape response (cessation of gill motion, elevation of the dorsal fin, flaring of the pectoral fins, and straightening of the body in response to tactile stimulation of the snout) there was an increase in the background discharge rate and a decrease in the sensitivity of the afferents to passively applied rotations. These effects were analogous to those observed during electrical activation of the efferent cell group. Indeed, increases in the firing rate of efferent fibers were noted at the onset of this behavior. These findings appear to suggest a different role for vestibular efferents in this species as compared with primates. However, the experimental paradigm differed significantly from that we have used in the present study in that the fish did not make active head movements during the periods of afferent recording. These responses may be a part of a more generalized arousal mechanism that involves the activation of vestibular efferents (e.g., a startle response). It would be informative to know the responses of vestibular afferents in toadfish during a more extensive repertoire of behaviors that include head movements during free swimming.

The previous study of the effects of efferent activation in 
barbiturate-anesthetized squirrel monkeys reported an increase in resting rate of most afferents after electrical stimulation of the efferent cell group in the brainstem (Goldberg and Fernández, 1980). These effects were greatest for irregularly discharging afferents. For the subset of canal afferents tested with passive rotations during efferent stimulation, a decrease in rotational sensitivity was observed, except in situations in which the efferent-induced increase in resting discharge rate prevented inhibitory cutoff in afferents. The results and conclusions were similar to those reported by Highstein and Baker (1985), Boyle and Highstein (1990), and Highstein (1991) and (1992), providing support for the hypothesis that a role of vestibular efferents is to increase the linear range of afferent responses during active head movements. The finding that activation of the efferent system decreases the rotational sensitivity of afferents gave rise to the notion that a copy of the head movement motor command might be used by the efferent vestibular system to cancel the modulation of afferent activity in response to active head motion (Purcell and Perachio, 2001). The proposed mechanism is analogous to the function of efferent system in the lateral line organs of fish (Roberts and Russell, 1972). However, the results of the present study are not compatible with this hypothesis, because afferent responses were comparable during self-generated and passive head-on-body rotations.

\section{Implications for the role of efferents in primates}

Studies over the past three decades have evaluated other hypotheses regarding the role of the vestibular efferent system. The efferents do not appear to modulate afferent responses during normal wakefulness because the spectrum of afferent responses is relatively the same for barbiturate-anesthetized and alert monkeys (Fernández and Goldberg, 1971; Keller, 1976; Lisberger and Pavelko, 1986). The premotor circuitry responsible for the control of eye movements also does not appear to influence afferent responses in that, for head-restrained animals, afferents are not modulated during saccadic eye movements or optokinetic nystagmus (Miles and Braitman, 1980). Furthermore, it is unlikely that neck proprioceptive inputs influence vestibular afferent responses, because second-order vestibular neurons in rhesus monkeys respond identically to head velocity during passive and active rotations of the head-on-body (Roy and Cullen, 2001, 2002). Finally, in the present study, we have demonstrated that these signals are also absent on afferents during self-generated, combined eye-head movements.

Since we have shown that efferents are not modulating the activity of semicircular canal afferents during self-generated head motion, what is their physiological role? One possibility is that they have a role in the long-term balancing of activity between the two labyrinths. In a role analogous to that shown for auditory efferents (Walsh et al., 1998), the vestibular efferent system might function to establish calibration of the afferent activity originating from the two labyrinths during development. Alternatively, the system could function after maturation to offset asymmetries in afferent resting rates and rotational sensitivities that would interfere with the function of vestibular reflexes (Lasker et al., 2000). Such asymmetries can occur during disease processes and, perhaps, as a consequence of the effects of aging on hair cells and afferents (Lopez et al., 1997). It is possible that efferents have a role in restoring symmetry to these processes. The slow component of excitation of vestibular nerve afferents observed after electrical activation of the efferents might underlie such a mechanism (Goldberg and Fernández, 1980). Another possibility is that activation of the efferent system has a differential influence on canal and otolith afferents. Efferents could function to offset the effects of gravity on otolith afferents, thereby maximizing the range available for encoding changes in linear acceleration.

\section{REFERENCES}

Bernard C, Cochran SL, Precht W (1985) Presynaptic actions of cholinergic agents upon the hair cell-afferent fiber synapses in the vestibular labyrinth of the frog. Brain Res 338:225-236.

Boyle R, Highstein SM (1990) Efferent vestibular system in toadfish: action upon horizontal semicircular canal afferents. J Neurosci 10:1570-1582.

Brichta AM, Goldberg JM (2000) Responses to efferent activation and excitatory response-intensity relations of turtle posterior-crista afferents. J Neurophysiol 83:1224-1242.

Cullen KE, Rey CG, Guitton D, Galiana HL (1996) The use of system identification techniques in the analysis of oculomotor burst neuron spike train dynamics. J Comp Neurosci 3:347-368.

Cullen KE, Roy JE, Sylvestre PA (2001) Signal processing by vestibular nuclei neurons is dependent on the current behavioral goal. Ann NY Acad Sci 942:345-363.

Fernández C, Goldberg JM (1971) Physiology of peripheral neurons innervating semicircular canals of the squirrel monkey. II. Response to sinusoidal stimulation and dynamics of peripheral vestibular system. J Neurophysiol 34:661-675.

Fuchs AF, Robinson DA (1966) A method for measuring horizontal and vertical eye movement chronically in the monkey. J Appl Physiol 21:1068-1070.

Gacek RR, Lyon M (1974) The localization of vestibular efferent neurons in the kitten with horseradish peroxidase. Acta Otolaryngol 77:92-101.

Gdowski GT, McCrea RA (1999) Integration of vestibular and head movement signals in the vestibular nuclei during whole-body rotation. J Neurophysiol 82:436-449.

Goldberg JM, Fernández C (1980) Efferent vestibular system in the squirrel monkey: anatomical location and influence on afferent activity. J Neurophysiol 43:986-1025.

Goldberg JM, Smith CE, Fernández C (1984) Relation between discharge regularity and responses to externally applied galvanic currents in vestibular nerve afferents of the squirrel monkey. J Neurophysiol $51: 1236-1256$.

Goldberg JM, Brichta AM, Wackym PA (2000) Efferent vestibular system: anatomy, physiology and neurochemistry. In: Neurochemistry of the vestibular system (Anderson JH, Beitz AJ, eds), pp 61-94. Boca Raton, FL: CRC.

Guitton D, Douglas RM, Volle M (1984) Eye-head coordination in cats. J Neurophysiol 52:1030-1050.

Highstein SM, Baker R (1985) Action of the efferent vestibular system on primary afferents in the toadfish, Opsanus tau. J Neurophysiol 54:370-384.

Highstein SM (1991) The central nervous system efferent control of the organs of balance and equilibrium. Neurosci Res 12:13-30.

Highstein SM (1992) The efferent control of the organs of balance and equilibrium in the toadfish, Opsanus tau. Ann NY Acad Sci 656:108-123.

Hullar TE, Minor LB (1999) High-frequency dynamics of regularly discharging canal afferents provide a linear signal for angular verstibuloocular reflexes. J Neurophysiol 82:2000-2005.

Keller EL (1976) Behavior of horizontal semicircular canal afferents in alert monkey during vestibular and optokinetic stimulation. Exp Brain Res 24:459-471.

Klinke R, Galley N (1974) Efferent innervation of vestibular and auditory receptors. Physiol Rev 54:316-357.

Lasker DM, Hullar TE, Minor LB (2000) Horizontal vestibuloocular reflex evoked by high-acceleration rotations in the squirrel monkey. III. Responses after labyrinthectomy. J Neurophysiol 83:2482-2496.

Lindeman HH (1969) Studies of the morphology of the sensory regions of the vestibular apparatus. Erg Anat 42:1-113.

Lisberger SG, Pavelko TA (1986) Vestibular signals carried by pathways subserving plasticity of the vestibulo-ocular reflex in monkeys. J Neurosci 6:346-354.

Lopez I, Honrubia V, Baloh RW (1997) Aging and the human vestibular nucleus. J Vestib Res 7:77-85.

Lysakowski A, Minor LB, Fernández C, Goldberg JM (1995) Physiological identification of morphologically distinct afferent classes innervating the cristae ampullares of the squirrel monkey. J Neurophysiol 73:1270-1281.

McCrea RA, Chen-Huang C, Belton T, Gdowski GT (1996) Behavior contingent processing of vestibular sensory signals in the vestibular nuclei. Ann NY Acad Sci 781:292-303.

Miles FA, Braitman DJ (1980) Long-term adaptive changes in primate vestibuloocular reflex. II. Electrophysiological observations on semicircular canal primary afferents. J Neurophysiol 43:1426-1436. 
Plotnik M, Marlinski V, Goldberg J (2000) Efferent-mediated type III rotational responses recorded from vestibular-nerve afferents in the chinchilla. Twenty-Third Annual Meeting of the Association for Research in Otolaryngology, St. Petersburg Beach, FL, February.

Purcell IM (1997) Three-dimensional analysis and patterns of innervation of vestibular efferent and afferent terminal endings in the semicircular canals and otolith organs of the gerbil. PhD dissertation, University of Texas-Galveston.

Purcell IM, Perachio AA (2001) Three-dimensional analysis of vestibular efferent neurons innervating semicircular canals of the gerbil. J Neurophysiol 78:3234-3248.

Rasmussen GL, Gacek RR (1958) Concerning the question of the efferent fiber component of the vestibular nerve of the cat. Anat Rec 130:361-362.

Roberts BL, Russell IJ (1972) The activity of lateral-line efferent neurons in stationary and swimming dogfish. J Exp Biol 57:435-448.

Rossi ML, Martini M (1991) Efferent control of posterior canal afferent receptor discharge in the frog labyrinth. Brain Res 555:123-134.
Roy JE, Cullen KE (1998) A neural correlate for vestibulo-ocular reflex suppression during voluntary eye-head gaze shifts. Nat Neurosci 1:404-410.

Roy JE, Cullen KE (2001) Selective processing of vestibular reafference during self-generated head motion. J Neurosci 21:2131-2142.

Roy JE, Cullen KE (2002) Vestibuloocular reflex signal modulation during voluntary and passive head movements. J Neurophysiol 87:2337.

Sans A, Highstein SM (1984) New ultrastructural features in the vestibular labyrinth of the toadfish, Opsanus tau. Brain Res 308:191-195.

Sylvestre PA, Cullen KE (1999) Quantitative analysis of abducens neuron discharge dynamics during saccadic and slow eye movements. J Neurophysiol 82:2612-2632.

Valli P, Botta L, Zucca G, Casella C (1986) Functional organization of the peripheral efferent system in the frog. Brain Res 362:92-97.

Walsh EJ, McGee J, McFadden SL, Liberman MC (1998) Long-term effects of sectioning the olivocochlear bundle in neonatal cats. J Neurosci 18:3859-3869. 